\title{
Anisotropy abrasive wear behavior of bagasse fiber reinforced polymer composite
}

\author{
Punyapriya Mishra ${ }^{1} \&$ S. K. Acharya ${ }^{2 *}$ \\ Department of Mechanical Engineering, National Institute of Technology, Rourkela-769008, Orissa, INDIA \\ *Corresponding Author: email-drsamirka@yahoo.com
}

\begin{abstract}
In this paper, an experimental study has been conducted to determine the abrasive wear behavior of bagasse fiber reinforced epoxy composite in different directions, namely parallel orientation (PO), anti-parallel orientation (APO) and normal orientation (NO) by using a two body abrasion wear tester. Three different types of abrasives wear behaviour have been observed in the composite in three orientations and follow the following trends: $\mathrm{W}_{\mathrm{NO}}<\mathrm{W}_{\mathrm{APO}}<\mathrm{W}_{\mathrm{PO}}$, where $\mathrm{W}_{\mathrm{NO}}, \mathrm{W}_{\mathrm{APO}}$ and $\mathrm{W}_{\mathrm{PO}}$ are the wear in normal, anti-parallel and parallel directions of fibres orientation, respectively. The fiber bundles present in the composite provide unique directional abrasive wear properties. Wear anisotropy magnitude of the composite is found to be a function of load and abrasive grit size. The worn surfaces were observed by using a SEM after the wear test. It has been found that in PO type samples the abrasion takes place due microploughing, where as in APO and NO type samples micro cutting found to be responsible for the wear process.
\end{abstract}

Key words: Bagasse fiber, SiC abrasive paper, abrasive wear, SEM

\section{Introduction}

In recent years increasing attention is being given on the use of natural fibers as a reinforcing component for the thermoplastics. The advantage of natural fibers over traditional reinforcing materials includes low density, low cost, biodegradability and recyclability etc (Mohanty et al, 2003, Baley, 2002, Van et al 2001). Due to such advantages, the natural fiber reinforced polymeric composites are widely used in manufacturing of many tribo components like production of bearing components used in automobile industries such as gears, wheels, buses etc (Tayeb et al, 1996, Chand et al, 2000, Hutton et al, 2001, Sampathkumaran et al, 2001). Sometimes these tribo components are subjected to abrasive wear either by sliding against a rough counter face or abrasion by hard particles. So the study of abrasive wear behavior of natural fiber reinforced polymer composite plays a vital role for tribological applications.

Natural fibers like kenaf (Nishino et al, 2003), jute (Gowda et al, 1999, Ray et al, 2001, Gassan et al, 2002), ramie, oil palm (Wollerdorfer et al, 1998) and hemp (Keller, 2003) are found to be good reinforcements for polymer composites. Amongst those, bagasse is as the remaining form after extraction of juice from the sugarcane. This fiber is mainly used as a combustible material for energy supply in sugarcane industries, as a pulp raw material in paper industries and also a reinforcing material for polymer composites (Cao et al, 2006). Monteiro et al, 1998 used sugarcane bagasse waste as reinforcement to polymeric resins and reported that composites with homogeneous microstructures could be fabricated and mechanical properties similar to wooden agglomerates can be achieved. Biliba et al, 2003 had utilized bagasse to make bagasse-cement composites for building industries. Little information concerning the tribological performance of natural fibre reinforced composite material (Yousif et al, 2006, Tong et al, 1998, Tong et al, 2005, Sayed et al, 1995) has been reported. The potential of sugarcane fiber/polyester composite for tribological applications has been studied in detail by Tayeb et al, 2008. Mahapatra et al. (2009) has studied the taguchi experimental technique for optimizing parameters like applied load, sliding velocity and fiber length. However, they have not reported anything about micro structural observations in their paper. Recently some attempt has been taken to study the wear anisotropy of natural fibers like cotton (Eleiche et al, 1986), bamboo (Chand et al, 2007a, 2007b), sisal (Tong et al, 1995), jute (Chand et al, 2007c), and kenaf (Chand et al, 2009). Amin et al, 1986 reported the effect of unidirectional cotton fiber 
reinforcement on the friction and sliding wear characteristics of polyester with varying sliding speed, fiber volume fraction, and fiber orientation. Chand et al, 2007a, 2007b studied the wear behavior of bamboo in different orientations such as LL, LT and TT, and observed that in bamboo the wear rate follows the trend $\mathrm{W}_{\mathrm{TT}}<\mathrm{W}_{\mathrm{LT}}<\mathrm{W}_{\mathrm{LL}}$. Chin et al, 2009 investigated wear and friction performance of kenaf fibers reinforced epoxy composite in three different fiber orientations with respect to the sliding direction and reported that the composite exhibited better wear performance in normal (N-O) compared to parallel (P-O), anti-parallel (APO) orientations.

Hence, the current work aims to investigate the potential of using bagasse fibres as reinforcement in polymer resin for tribological application. In fibre reinforced composite, structure, dimension and orientation of fibres are important factors for their tribological properties. Wear data on natural composite structure bagasse can provide ideas for the design of bagasse based composite for tribological applications, for example anti-friction materials and wear resistant materials. Hence the effects of load and the grit size of abrasives upon the abrasion wear performance of the bagasse fiber reinforced polymer composite in three different orientations of fiber (P, AP, and N) were evaluated. The wear mechanisms were also comparatively discussed, based on scanning electron microscopic examination.

\section{Experimental}

\subsection{Sample preparation}

The type of epoxy resin used in the present investigation is LY 556. It possesses a density of $1.1 \mathrm{gm} / \mathrm{cm}^{3}$. The low temperature epoxy resin and corresponding hardener (HY951) are supplied by Ciba- Geigy of India Limited. Fresh bagasse fibers were collected from Shakti Sugar Limited, located in Dhenkanal, Orissa, India. These fibers were then cleaned with pressurized water to remove sugar residues and organic materials and then dried with compressed air before using them for preparation of composite. In earlier studies the authors (S.K.Acharya et al, 2008) reported $20 \%$ fiber volume fraction to be optimized for the composite developed. Hence in the present work same 20\% fiber volume fraction has been utilized for preparation of the composite. Composites were prepared by using resin to hardener ratio as 10:1. Usual hand lay-up technique was used to manufacture the composite sheet at room temperature. Samples were cut in a standard size of $20 \times 20 \times 20 \mathrm{~mm}^{3}$ and polished before testing on a TwoBody Abrasion Tester. Schematic diagram of composites showing different fiber orientations and sliding direction with designations of samples are shown in Figure-1.
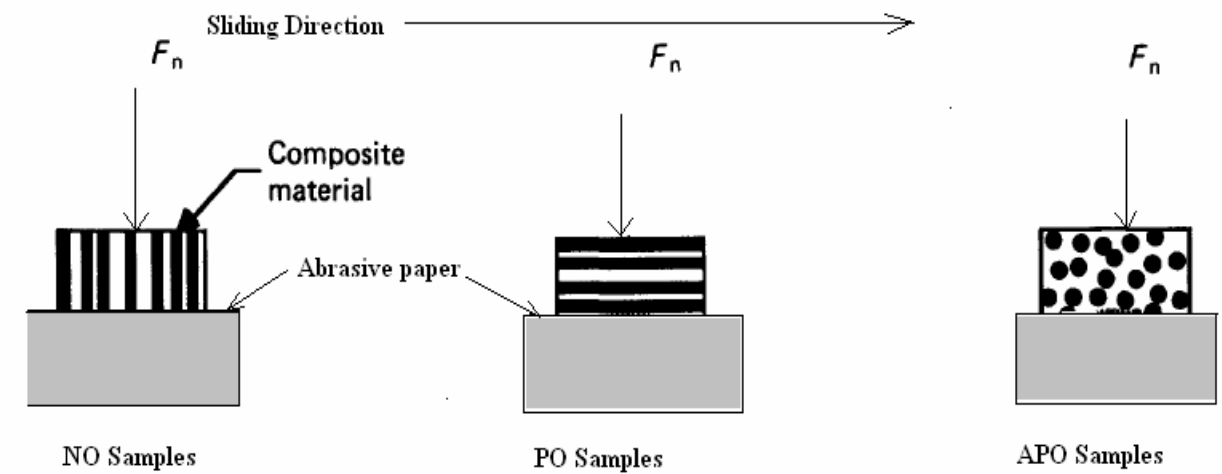

Figure 1. Schematic diagram of different fiber oriented composite with respect to sliding direction

\subsection{Abrasive wear testing}

Experiments were performed on composite samples by using a two body abrasive wear tester supplied by magnum engineers, Bangalore, India. The rectangular specimen of $20 \mathrm{mmX} 20 \mathrm{~mm}$ were abraded on water proof silicon carbide (SiC) abrasive papers of different grit sizes (150, 180, 320 and 400) which were properly fixed on the machine bed. The experiments were conducted at a constant sliding speed of $1000 \mathrm{~mm} / \mathrm{min}$. Four different loads $1,3,5$ and $7 \mathrm{~N}$ were applied on the specimen. Wear rate was estimated by measuring the weight loss of the specimen after each test. The weight loss was calculated by taking the weight difference of the sample before and after each test. The weight loss:

$$
(\Delta w)=\left(w_{a}-w_{b}\right) \text { gm }
$$

where $\Delta w$ is the weight loss in gm and $w_{a}$ and $w_{b}$ are the weight of the sample after and before the abrasion test in gm. The abrasive wear rate $(W)$ can be calculated by using the following formula: 


$$
W=\frac{\Delta w}{\left(\rho \times S_{d}\right)}
$$

where ' $W$ ' is the wear rate in $\mathrm{cm}^{3} / \mathrm{m}$, ' $\rho$ ' is the density of the composite, $\Delta w$ the weight loss in gm and ' $S_{d}$ ' is the sliding distance in $\mathrm{m}$. The weight loss was measured at a sliding distance of $27 \mathrm{~m}$. Sliding tests were conducted for parallel orientation (P-O), antiparallel orientation (APO) and normal orientation (NO) of BFRP composite with respect to the sliding direction.

\subsection{SEM Studies}

Scanning electron microscope (SEM) was used to study the fibres and the fractured surfaces of composite specimens.

\section{Results and discussion}

\subsection{Effect of load on wear rate}

Figures 2-5 show the variation of wear rate with different loading conditions for 150, 180, 320 and 400 grit size abrasives respectively.

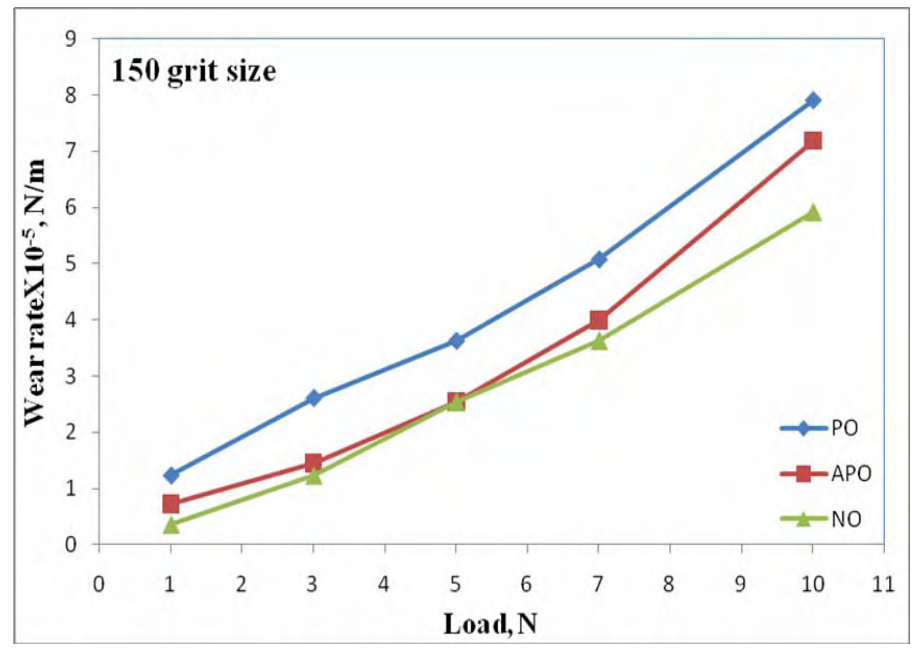

Figure 2. Variation of wear rate with load at 150 grit size abrasives for P, AP and $\mathrm{N}$ orientation of fiber samples

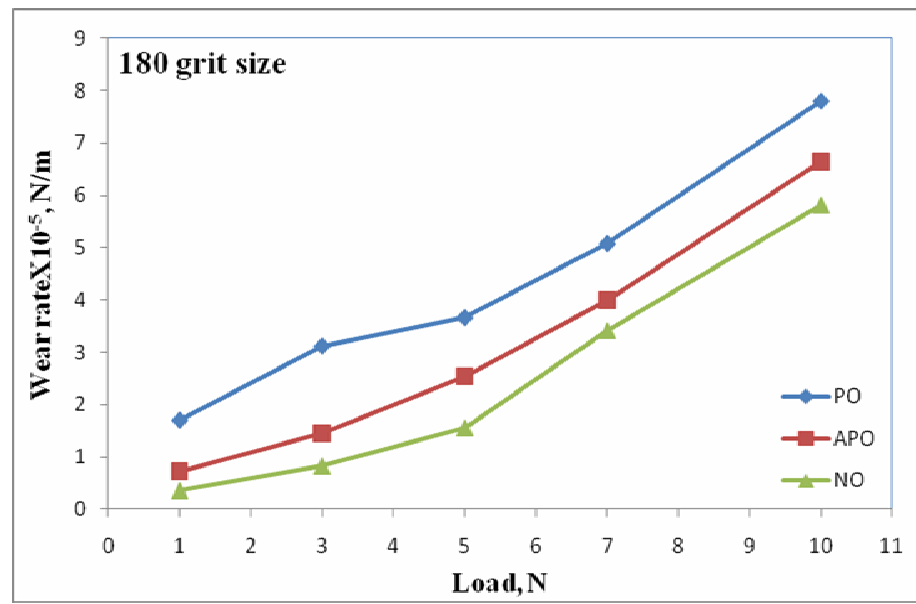

Figure 3. Variation of wear rate with load at 180 grit size abrasives for $\mathrm{P}, \mathrm{AP}$ and $\mathrm{N}$ orientation of fiber samples

It is observed from the graphs that for all grit sizes the wear rate increases with the increase of load. Under lower loading conditions ( 1 and $3 \mathrm{~N}$ ), the degree of penetration of abrasive particle on the surface of the composite is less resulting in a lower 
material removal (Figure 6a). As the normal load on the abrasive particles increased, the load distributed over all the asperities and each asperity penetrates deeper into the surface. That means a larger depth of grooves was occurred. Deeper grooving caused higher wear rate. This resulted in more material removal by a severe plastic deformation which appeared as a series of grooves parallel to the sliding direction in the SEM micrograph (Figure 6b).

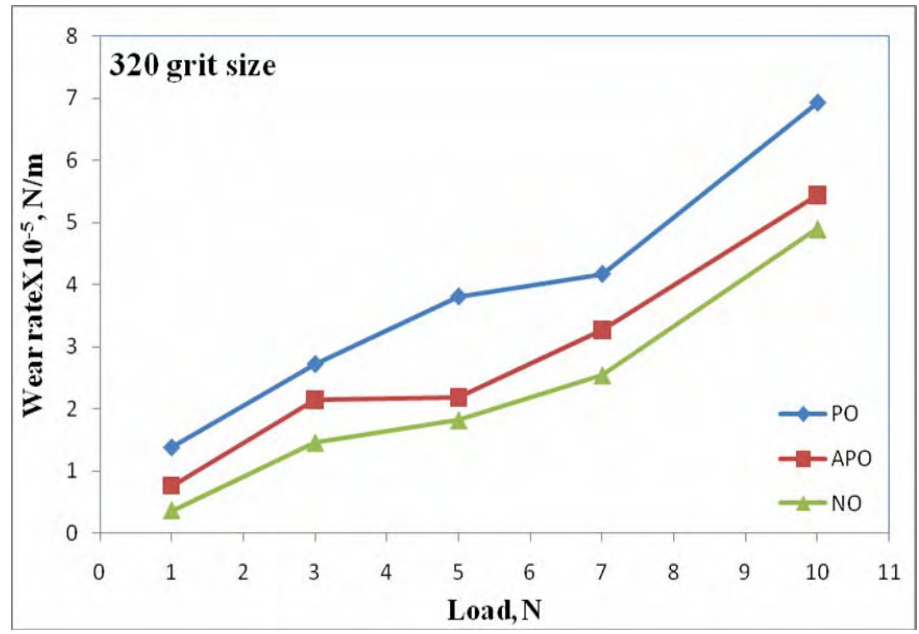

Figure 4. Variation of wear rate with load at 320 grit size abrasives for $\mathrm{P}$, AP and N orientation of fiber samples

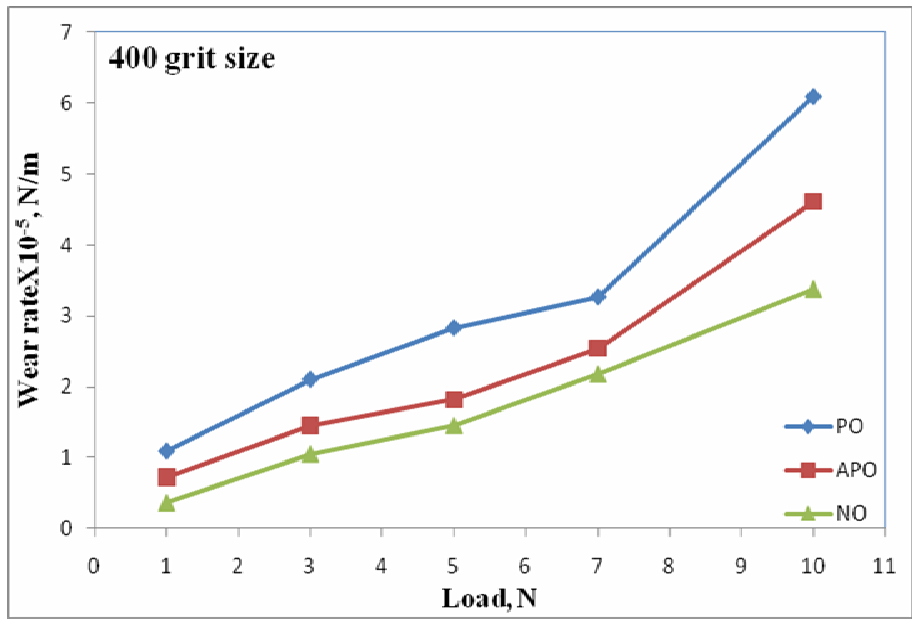

Figure-5 Variation of wear rate with load at 400 grit size abrasives for P, AP and N orientation of fiber samples

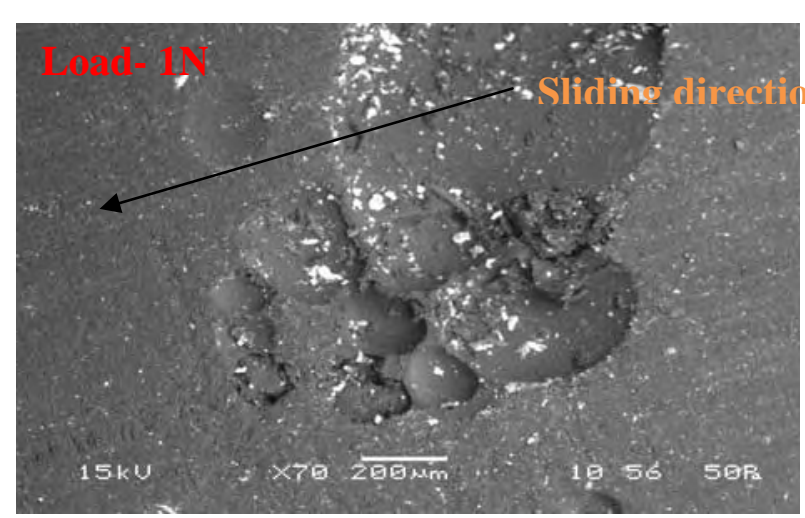

(a)

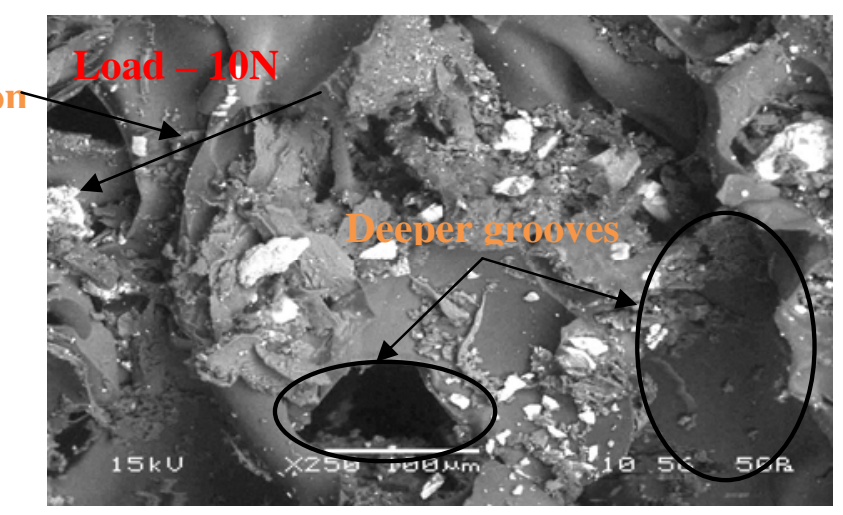

(b)

Figure 6. SEM micrographs of abraded surface (a) at $1 \mathrm{~N}$ load and (b) at $10 \mathrm{~N}$ load 


\subsection{Effect of grit size}

Figure 7 shows the variation of wear rate with grit sizes at a load of $10 \mathrm{~N}$. With increase of the abrasive grit size from 400 to 150 , wear rate increases for all PO, APO and NO samples. As pointed by Chand et al, 2007a, the wear rate is primarily dependent on the depth and width of the groove made by the abrasives. At coarser abrasives, the depth of penetration of the abrasive particle is so high that a large portion of material is removed from the specimen surface leaving behind large cavities in the worn surface. The depth of cut is increased significantly with coarser grit size. If the applied load is fixed, then the effective stress on individual abrasives increases with coarser abrasive particles, as the load is shared by less number of abrasives. When the abrasive particles are finer in size, they make only elastic contact with the test specimen surface, as the effective stress in individual abrasive is less. As a result, these abrasive particles only support the applied load without contributing sufficient material removal.

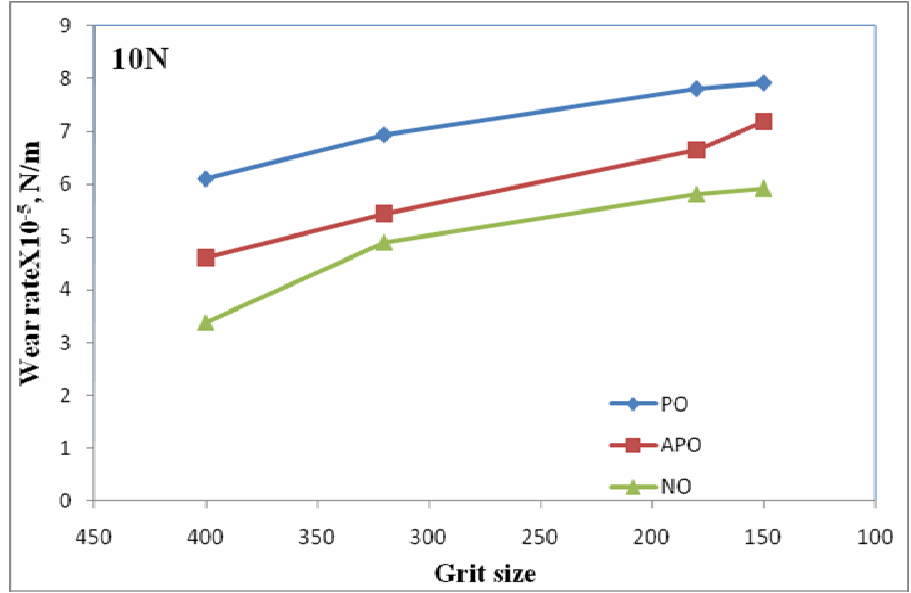

Figure 7. Variation of wear rate with grit size at a load of $10 \mathrm{~N}$ for $\mathrm{P}, \mathrm{AP}$ and $\mathrm{N}$ orientation of fiber samples

The radius of abrasive tip is varying with increase size. But the width of groove increases substantially with increase in abrasive size. This may be attributed to the fact, the effective stresses on each individual abrasive increase substantially when become coarser in size, and make it more effective to penetrate deeper into the surface. Similar trend is also followed for the variation of wear rate with grit size at $1,3,5,7 \mathrm{~N}$ loads.

\subsection{Effect of orientation of fiber}

Experiments were conducted on composites with three different orientation of fibers i.e. parallel orientation (PO), anti-parallel orientation (APO) and normal orientation (NO). The results show (Figures 2-5 and 7) the PO samples had the maximum wear rate than those of the APO and NO samples but with varying magnitude at different loading conditions and grit sizes. So the wear rate follows the trend: $\mathrm{W}_{\mathrm{NO}}<\mathrm{W}_{\mathrm{APO}}<\mathrm{W}_{\mathrm{PO}}$.

In case of parallel orientation (PO), the matrix material between fibres was removed allowing for the subsequent removal of whole fiber during abrasion, which is visible in SEM (figure 8a). The possibility of the real contact area with fibres in the sliding direction is more in PO samples than the APO and NO sample, which led to the highest wear.

In APO samples, hard abrasive particles were moving through different interfaces and different layers of matrix and fibre bundle alternatively. So the composite in APO was subjected to micro-cutting action that was hampered due to phase discontinuity, which was alternately coming after every fibre/matrix. Thus in this mode the removal of material was due to micro-cutting in the resin matrix and, bending and tearing of fibre transversely at their ends (Figure $8 \mathrm{~b}$ ).

In case of normal fibre direction (NO) (Figure 8c), there is more resistance to the removal due to deeply embedded long fibers in the matrix. The cellulosic fibers are oriented normal to the sliding direction, only cross section of vascular bundles come in contact to the abrasive particles and could not remove the material easily. The cross sections of vascular bundle of fibres created more resistance in the path of the abrading particles and restricted the movement of abrading particles, which reduced the wear in the NO sample. 


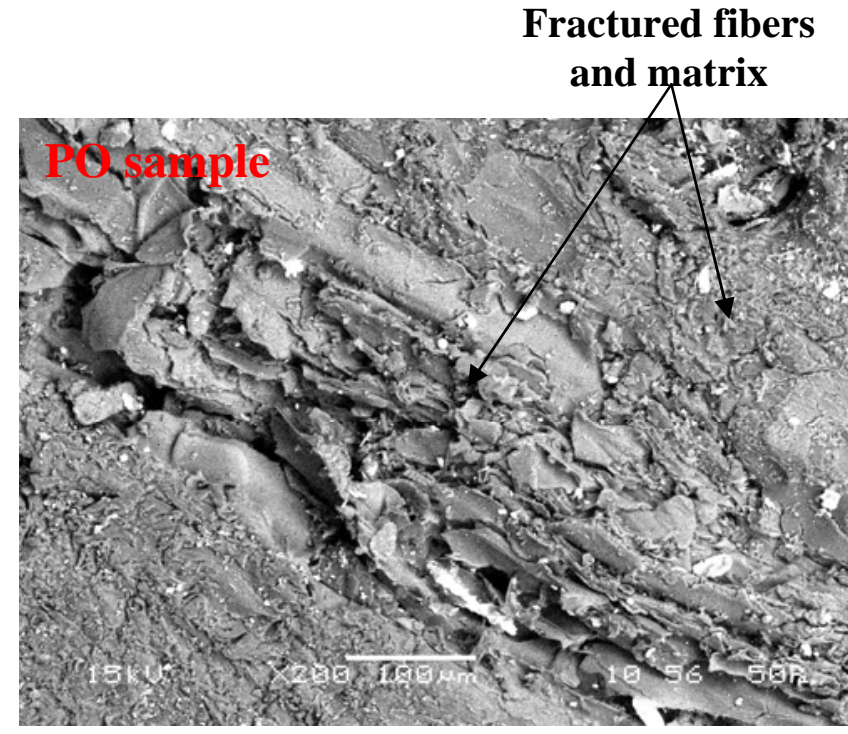

(a)



(b)

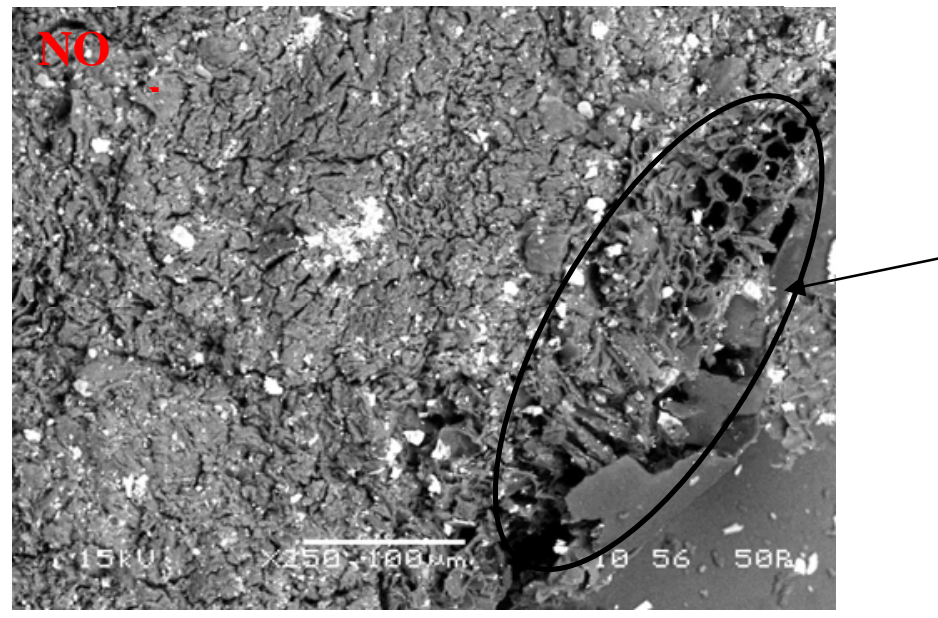

Cross-section of Vascular bundle of fibers

(c)

Figure 8. SEM micrographs of abraded surface of (a) PO and (b) APO and (c) NO samples

\subsection{Variation of anisotropy co-efficient with load and grit size}

Anisotropy coefficient is defined as the ratio of the wear loss value in perpendicular to parallel fibre direction in unidirectional fibre reinforced composites (Chand et al, 2007a). Physical significance of anisotropy coefficient is to show the anisotropy magnitude of material property in the composites. Anisotropy coefficient can be written Anisotropy coefficient $(n)=\mathrm{W}_{\mathrm{NO}} / \mathrm{W}_{\mathrm{PO}} \quad$ (if property $W$ is less in NO case than PO case)

or $\quad n=\mathrm{W}_{\mathrm{PO}} / \mathrm{W}_{\mathrm{NO}} \quad$ (if property $W$ is less in $\mathrm{PO}$ case than NO case)

$n=1$ for isotropic composites; $n=0$, for ideal anisotropic composites (or Infinite anisotropic composites); $0<n<1$ for anisotropic composites.

Generally the value of anisotropy coefficient will lie between 0 and 1 . In the present case, the wear rate of NO samples is less than that of the PO samples. So $\mathrm{n}=\mathrm{W}_{\mathrm{NO}} / \mathrm{W}_{\mathrm{PO}}$. The dependency of wear anisotropy coefficient for different loads and different abrasive grit size for bagasse fiber polymer composite has also been determined in this study. Figure 9 shows the variation of wear anisotropy coefficient with different applied loads 1, 3, 5, 7 and $10 \mathrm{~N}$ for $27 \mathrm{~m}$ sliding distance. It was observed that with increase of load from 1 to $10 \mathrm{~N}$, the wear anisotropic coefficient increases up to7N and further increase in load it decreases. Minimum anisotropy occurred at $7 \mathrm{~N}$ load. The observed trend of wear anisotropy coefficient is a function of load and approaching to 
maximum value or near to one (which is the indication to become nearly isotropic behavior). From the relationship for the wear anisotropy as proposed by Chand et al, 2007a the relationship for the present case is found to be

$$
W_{N O} / W_{P O}=-a L^{2}+b L-c
$$

where $W_{N O}$ and $W_{P O}$ are the wear in normal and parallel directions of fibres orientation and $L$ is the applied load. Constants $a, b$ and $c$ for bagasse fiber polymer composite are $0.006,0.102$, and 0.236 , respectively.

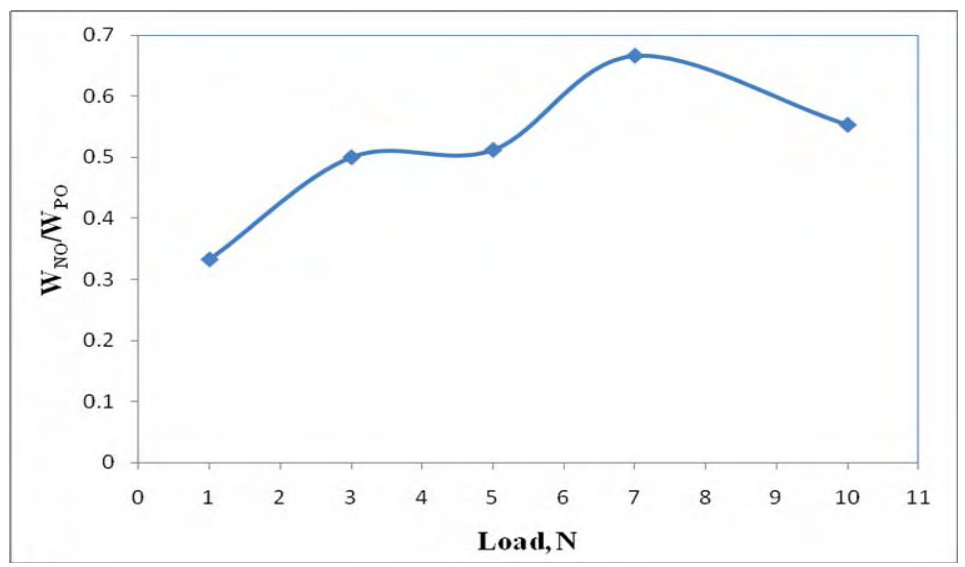

Figure 9. Graph between wear anisotropy vs load for BFRP composite

Figure 10 shows the dependence of wear anisotropy on different abrasive grit size. With increase of grit size, wear rate increases. But this experimental study exhibited the decreasing trend of wear anisotropy coefficient with increasing abrasive grit size and the peak in the anisotropy has been occurred at 400 grit size. The relationship between wear anisotropy coefficient and grit size is found to be

$$
W_{N O} / W_{P O}=-e S^{3}+f S^{2}-g S+h
$$

where $S$ is the abrasive grit size and $e, f, g$ and $h$ are constants. The coefficient of correlation $\mathrm{R}^{2}$ value is 1 . Values of constants $e, f$, $g$ and $\mathrm{h}$ are $3 \mathrm{E}-08,2 \mathrm{E}-05,0.0032$ and 0.9577 respectively at $27 \mathrm{~m}$ sliding distance.

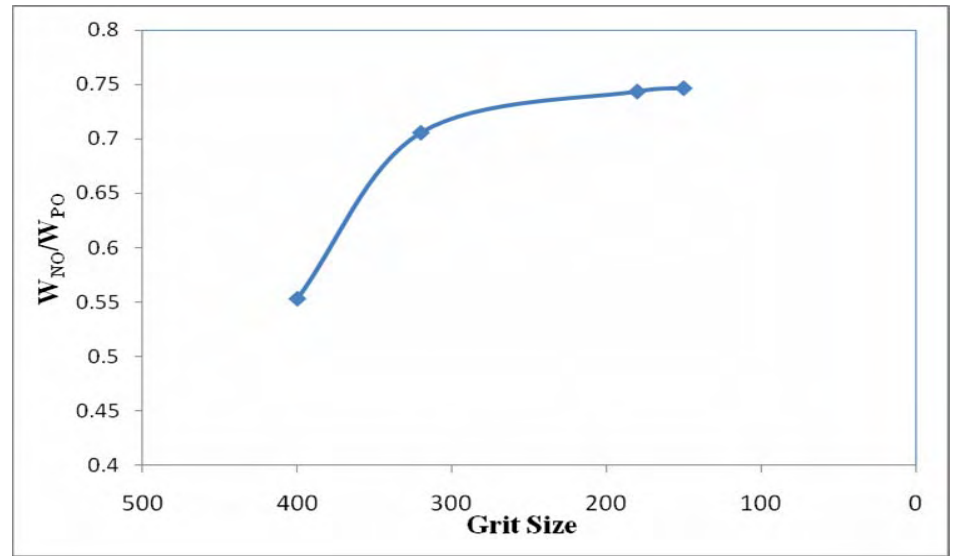

Figure 10. Graph between wear anisotropy vs grit size for BFRP composite

\section{Conclusion}

The following conclusions are drawn from the present study.

o Abrasive wear rate of BFRP composite strongly depends upon load and abrasive grit size. With increase of load and grit size wear rate increases.

o The orientation of fiber in composites has a significant influence on the wear rate of composite.

0 The wear rate of PO samples is greater than that of the APO and NO samples. It follows the trend $\mathrm{W}_{\mathrm{NO}}<\mathrm{W}_{\mathrm{APO}}<\mathrm{W}_{\mathrm{PO}}$.

o The wear anisotropy of unidirectional bagasse fiber reinforced polymer composite depends on load and grit size. 
o A relationship of wear anisotropy with load and grit size has been evaluated.

o This method can be further extended to hybrid composite structure.

\section{References}

Acharya S.K., Mishra P., Mehar S.K., Dikshit V. 2008. Weathering behavior of bagasse fiber reinforced polymer composite. Journal of reinforced plastics and composite, Vol. 27, No.16, pp.1839-1846.

Baley C. 2002. Analysis of the flax fibers tensile behavior and analysis of the tensile stiffness increase. Composites part A: Applied Science and Manufacturing, Vol.33, No.7, pp.939-348.

Bilba K, Arsene M.A., Quensanga A. 2003. Sugar cane bagasse fibre reinforced cement composites. Part I. Influence of the botanical components of bagasse on the setting of bagasse/cement composite. Cement Concrete Composite, Vol.25, pp. 91-96.

Cao Y., Shibata S., Fokumoto I. 2006. Mechanical properties of biodegradable composites reinforced with bagasse fiber before and after alkali treatment. Composites Part A: Applied Science and Manufacturing, Vol.37, No.3, pp. 423-429.

Chand N., Dwivedi U.K. and Acharya S.K. 2007a. Anisotropic abrasive wear behaviour of bamboo (Dentrocalamus strictus). Wear, Vol.262, pp. 1031-1037.

Chand N. and Dwivedi U.K. 2007b. High stress abrasives wear study on bamboo. Journal of Materials Processing Technology, Vol.183, pp. 155-159.

Chand N. and Dwivedi U.K. 2007c. Influence of fiber orientation on high stress wear behavior of sisal fiber-reinforced epoxy composites. Polymer composites, Vol. 28, p. 437-441.

Chand N., Naik A., Neogi S. 2000. Three-body abrasive wear of short glass fibre polyester composite. Wear, Vol.242, pp.38-46.

Chin C.W., Yousif B.F. 2009. Potential of kenaf fibres as reinforcement for tribological applications. Wear, Vol.267, No.9-10, pp. 1550-1557.

Dwivedi U.K. and Chand N. 2009. Influence of fibre orientation on friction and sliding wear behaviour of jute fibre reinforced polyester composite. Applied Composite Material, Vol.16, pp. 93-100.

Eleiche A.M., Amin G.M. 1986. The effect of unidirectional cotton fibre reinforcement on the friction and wear characteristics of polyester. Wear, Vol.112, pp.67-68.

El-Sayed A.A., El-Sherbiny M.G., Abo-El-Ezz A.S., Aggag G.A. 1995. Friction and wear properties of polymeric composite materials for bearing applications. Wear, Vol.184, pp. 45-53.

El-Tayeb N.S.M. 2008. A study on the potential of sugarcane fibers/polyester composite for tribological applications. Wear, Vol.265, pp. 223-235.

El-Tayeb N.S.M., Mostafa I.M. 1996. The effect of laminate orientations on friction and wear mechanisms of glass reinforced polyester composite. Wear, Vol.195, pp.186-191.

Gassan J. 2002. A study of fiber and interface parameters affecting the fatigue behavior of natural fiber composites. Composites Part A: Applied Science and Manufacturing, Vol.33, pp. 369-374.

Gowda T.M., Naibu A.C.B., Chhaya R. 1999. Some mechanical properties of untreated jute fabric-reinforced polyester composites. Composites part A: Applied Science and manufacturing, Vol.30, pp. 277-284.

Hutton T.J., Johnson D., McEnaney B. 2001. Effects of fiber orientation on the tribiology of a model carbon-carbon composite. Wear, Vol.249, pp.647-655.

Keller A. 2003. Compounding and mechanical properties of biodegradable hemp fiber composites. Composites Science and Technology, Vol.63, pp. 1307-1316.

Kishore, Sampathkumaran P., Seetharamu S., Murali A., Kumar R.K.2001. On the SEM features of glass-epoxy composite system subjected to dry sliding wear. Wear, Vol.247, pp. 208-213.

Mahapatra S.S., Chaturvedi Vedansh. 2009. Modelling and analysis of abrasive wear performance of composites using Taguchi approach. International journal of Engineering, Science and Technology, Vol.1, No. 1, pp.123-135.

Mohanty A.K., Wibowo A., Misra M., Drzal L.T. 2003. Effect of process engineering on the performance on natural fiber reinforced cellulose acetate biocomposites. Composites part A: Applied Science and Manufacturing, Vol.35, No.3, pp.363-370.

Monteiro S.N., Rodriquez R.J.S., De Souza M.V., D'Almeida J.R.M. 1998. Sugar Cane Bagasse Waste as Reinforcement in Low cost composites. Advanced performance Material, Vol.5, No.3, pp. 183-191.

Nishino T., Hirao K., Kotera M., Nakamae K., Inagaki H. 2003. Kenaf reinforced biodegradable composite. Composites Science and Technology, Vol.63, pp. 1281-1286.

Ray D., Sarkar B.K., Rana A.K., Bose N.R. 2001. The mechanical properties of vinyl ester resin matrix composites reinforced with alkali-treated jute fibres. Composites Part A: Applied Science and Manufacturing, Vol.32, pp. 119-127.

Ren L., Tong J., Arnell R.D. 1998. Dry sliding wear behaviour of bamboo. Wear, Vol.221, pp. 37-46.

Tong J., Ren L., Li J., Chen B. 1995. Abrasive wear behaviour of bamboo. Tribology International, Vol.28, No.5, pp. 323-327.

Tong J., Ma Y., Chen D., Sun J., Ren L. 2005. Effects of vascular fiber content on abrasive wear of bamboo. Wear, Vol.259, pp. 78-83.

Van Voorn B., Smit H.H.G., Sinke R.J., de Klerk B. 2001. Natural fibre reinforced sheet moulding compound. Composites part A: Applied Science and Manufacturing, Vol.32, No.9, pp.1271-1279. 
Wollerdorfer M., Bader H. 1998. Influence of natural fibers on the mechanical properties of biodegradable polymers. Industrial Crops and Products, Vol.8, pp. 105-112.

Yousif B.F., EL-Tayeb N.S.M. 2006. Mechanical and tribological characteristics of OPRP and CGRP composites. in: The Proceedings ICOMAST, GKH Press, Melaka, Malaysia, pp. 384-387, ISBN 983-42051- 1-2.

\section{Biographical notes}

Dr. S.K Acharya is an Associate Professor in the Department of Mechanical Engineering, National Institute of Technology Rourkela, India. He has more than 24 years of experience in teaching and research. His current area of research includes Tribology, Composite materials and Nano Technology. He has published more than thirty papers in referred national and international journals. He has also presented more than seventy five research articles in national and international conferences.

Mrs Punya Priya Mishra is a PhD student in Mechanical Engineering Department, National Institute of Technology Rourkela, India. She is pursuing her thesis work on Preparation and characterization of bagasse fiber reinforced polymer composite. Her current area of research includes Natural fiber composite for Tribological applications. She has recently joined as lecturer in Mechanical Engineering Department, VSSUT, Burla, ORISSA, INDIA. She has published eight journal papers and presented fifteen papers in different national and international conferences.

Received December 2010

Accepted December 2010

Final acceptance in revised form December 2010 